\title{
Research Paper: An Investigation of the Social Function of Children With Cerebral Palsy of 2-6 Years Old
}

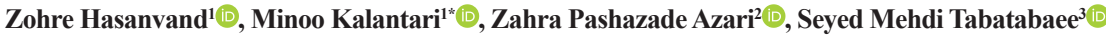 \\ 1. Department of Occupational Therapy, School of Rehabilitation, Shahid Beheshti University of Medical Sciences, Tehran, Iran \\ 2. Department of Rehabilitation Sciences, University of Social Welfare and Rehabilitation Sciences, Tehran, Iran. \\ 3. Department of Biostatistics, School of Allied Medical Sciences, Shahid Beheshti University of Medical Sciences, Tehran, Iran.
}

Article info:

Received: 10 Sep 2017

Accepted: 15 Jan 2018

\section{Keywords:}

Cerebral palsy, Children, Social skills, Motor skills
Citation: Hasanvand Z, Kalantari M, Pashazade Azari Z, Tabatabaee SM. An Investigation of the Social Function of Children With Cerebral Palsy of 2-6 Years Old. Iranian Rehabilitation Journal. 2018; 16(2):163-168. http://dx.doi.org/10.32598/irj.16.2.163

: http://dx.doi.org/10.32598/irj.16.2.163

\begin{abstract}
A B STRACT
Objectives: Children who have a disorder in motor function often suffer from disorders in other areas of their daily lives, such as social and communicative functions. The social function of children with cerebral palsy has so far been less studied than other aspects. The purpose of this study was to evaluate the social function of children with cerebral palsy of 2 to 6 years old.

Methods: This (cross-sectional) descriptive-analytic study was performed on 100 children with cerebral palsy in two age groups of 2-4 and 4-6 years old who were selected through convenient sampling from the centers for occupational therapies in Isfahan city. Children's motor function was classified according to Gross Motor Function Classification System (hereafter, GMFCS). The social function was completed by filling in the Pediatric Evaluation of Disability Inventory (PEDI) by interviewing the parents. Statistical analysis was done.

Results: The statistical analyses of this study showed that there was a significant difference between the mean score of social function in 5 levels of motor function of children with cerebral palsy $(\mathrm{P}<0.0001)$. There was also a significant relationship between the age of children and their social function score $(\mathrm{r}=0.265$ and $\mathrm{P}=0.008)$. Moreover, the mean scores of social function in the first and second levels of GMFCS had a significant difference in both groups $(\mathrm{P}=0.002)$; however, this difference was not significant in the other three levels $(0.053<\mathrm{P}<0.647)$. Also, there was no significant difference between the mean score of social function of girls and that of boys $(\mathrm{P}=0.819)$.

Discussion: The gross motor function of children with cerebral palsy is related to their social function. This means that the lower the gross motor function of children with cerebral palsy in the GMFCS system, the higher is their social function in both age groups of 2-4 and 4-6 years. The highest score of social function was related to the first level, which has the best motor function. As the level of gross motor function increases, the score decreases. Also, in this study, the comparison of social function, in two age groups, at the corresponding levels of GMFCS showed that with increasing motor constraints with age, no significant progress was made in the social function of children with cerebral palsy. Therefore, in addition to physical interventions, social interventions should be considered for children with cerebral palsy.
\end{abstract}




\section{Introduction}

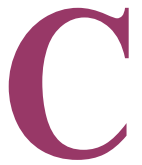

erebral Palsy (CP) is the most common non-progressive abnormality of the developing brain, with its most common cause being reported as premature. This disorder begins in the early childhood and remains throughout the life of the individual; therefore, its complications remain throughout the person's life [1]. The prevalence of this disease is about 3 per 1000 live births worldwide, and in Iran, the prevalence is increasing and accounts for about 2 to 4 cases per 1000 live births. Movement disorders of CP can affect normal sensory function, learning, communication, and behavior of the individual and affect the social skills and social interaction in these children [1-3]. Therefore, in addition to motor, posture and balance problems, these children suffer from problems such as abandonment, laziness, learning disruption, lack of social development, fear, and depression [4]. Social function is the ability of a person to establish social interactions and have successful communication in the society [5]. Social function can provide opportunities for self-confidence development for building friendly relationships and a meaningful life. This is while people with CP participate more in home-based activities and have fewer social experiences with friends and people with no movement problems. People with CP have expressed concern about having friends of their age and limited opportunities to engage with people outside the family $[6,7]$.

Research suggests that in children with a history of $\mathrm{CP}$ over 5 years of age, especially children who cannot walk without help, changes may be observed in social work activities at home, at school, in the community, and during social participation [8]. In addition, researchers found that children with $\mathrm{CP}$ who reach adulthood do not have the opportunity to participate in new social roles in their peers' groups; thus, they isolate themselves into impotent social activities. Research in recent years on the social problems of children with CP suggests the need to review this issue $[9,10]$. A study by Van Schie et al. (2013) showed that the motor inability of children with $\mathrm{CP}$ can lead to social function restrictions. Compared with normal children, more than half of the children with $\mathrm{CP}$ had restrictions at all levels of motor function classification in social function. One of the reasons for limiting the social function of children with motor problems may be the inability of these children to engage in social activities with their peers. Therefore, independent movement is important for establishing social interactions [11, 12]. Beckung et al. (2002), in a study conducted on children aged 8 to 5 years old with $\mathrm{CP}$, stated that the limi- tation in social communication between these children could be related to disability in motor learning, gross motor function, and hand movements [13].

Investigation of the social capacity and ability of preschool children with CP leads to the conclusion that the development of social functioning of these children, before and after their interactions in the context of the school, is influenced by what is being discussed. Early interventions based on these cases are done in order to develop their social interactions in school and community $[2,14]$. Since any person with CP, like any other human being, has a range of social needs, such as social communication and interactions with his or her environment, the question arises as to whether or not the social function of the person will be better with improved level of motor function or higher age and vice versa. To the best of our knowledge, no study has so far been carried out in Iran to examine the status of the social function of children with $\mathrm{CP}$ and its relationship with issues such as the level of motor function and their age. The studies that have so far been conducted in other countries in this field have generally emphasized the relationship between gross motor function and social function of children with CP. Moreover, factors such as the age of these children and the comparisons of their social function at the corresponding levels of the Gross Motor Function Classification System (GMFCS), according to the age groups specified in this system, have not yet been investigated. Therefore, the purpose of this study was to evaluate the social function of children with $\mathrm{CP}$ in two age groups of 2-4 and 4-6 years. The results of this study can help the therapists and families with disabilities to seek more targeted and comprehensive interventions.

\section{Methods}

The present study is a cross-sectional descriptive research. The samples were selected using convenient sampling technique from among children with $\mathrm{CP}$ who were referred to the centers for occupational therapies in Isfahan. The inclusion criteria were: 1 . Diagnosis of CP reported by a neurologist; 2 . Children aged $2-6$ years; 3 . Lack of social skill interventions so far; and 4. Children who were not blind or deaf. Also, the exclusion criteria were: parents' unwillingness to participate in all stages of the research and incomplete questionnaires. Initially, consent was received from parents of children to enter this study, and then a demographic questionnaire for children was completed.

The level of gross motor function was determined using the GMFCS system. In order to examine the social func- 
Table 1. The mean(SD) of social function score based on gross motor function classification system in two age groups of 2-4 and 4-6 years old

\begin{tabular}{cccccccc}
\hline & \multicolumn{3}{c}{ 2-4 Years Old } & \multicolumn{3}{c}{ 4-6 Years Old } \\
\cline { 2 - 8 } & Number & Mean & SD & Number & Mean & SD \\
\hline Level I & 10 & 77.20 & 10.68 & 10 & 86.60 & 2.17 \\
Level II & 10 & 61.40 & 19.87 & 10 & 79.70 & 6.61 \\
\hline Level III & 10 & 48.30 & 6.99 & 10 & 50.50 & 21.80 \\
\hline Level IV & 10 & 32.70 & 8.30 & 10 & 42.30 & 10.10 \\
\hline Level V & 10 & 14.20 & 5.28 & 10 & 13.60 & 6.22 \\
\hline Total & 50 & 46.76 & 24.70 & 50 & 54.54 & 28.93 \\
\hline
\end{tabular}

Iranian Rehabilitation Journal

tion of the samples, the social function capacity section in the Pediatric Evaluation Disability Inventory (PEDI) was used, which was completed by interviewing parents with an occupational therapist. The Mann-Whitney test was used to determine the relationship between the rank variables, and Kruskal-Wallis test and Spearman correlation coefficient were used to determine the relationship between the variables in both groups.

\section{Instruments}

The following data collection tools were used in the present study:

\section{Gross Motor Function Classification System (GMFCS)}

The GMFCS is a standard observational classification system that divides children with CP based on current gross motor skills, limitation in gross motor function,

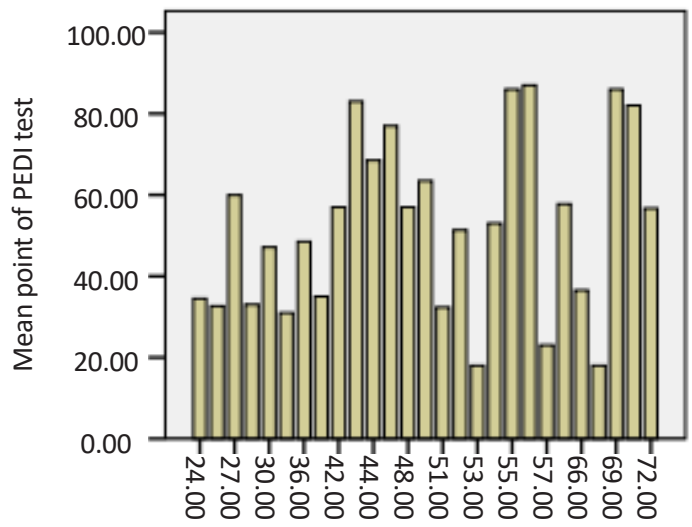

Age

Iranian Rehabilitation \ournal

Figure 1. The mean score of social function in terms of age and the need for technology and helping equipment in five levels. The level 1 exhibits maximum independence in motor function, and level 5 shows minimum independence in motor function. This instrument is used for the age groups of $0-2,2-4,4-6$ and 6-12 years. This test is one of the valid tests and is widely used globally. It was translated into the Persian language by Leila Dehghan et al (2009) in Tehran University of Medical Sciences and reported that this tool could be used to classify people with $\mathrm{CP}[15,16]$. Its reliability has also been confirmed.

\section{Pediatric Evaluation of Disability Inventory (PEDI)}

The PEDI is a comprehensive and standard scale for measuring function capacity in three areas of self-care, mobility, and social function in retarded children in the age range of 6 months to 7.5 years. Depending on the therapeutic priorities or the therapist's diagnosis, these three domains are used independently. In this study, the social function capacity was used to measure the social capability of children with CP. The translation, validity and reliability of this test in Iran were done and standardized by Moradi et al in 2015. In investigating the internal consistency, a high Cronbach's alpha coefficient (94\%$98 \%$ ) was obtained. The higher the score in this questionnaire, the better is the social function of the child $[2,17]$.

\section{Results}

This study was done on 100 children with CP. Among them, 44 children were male (44\%), and 56 children were female (56\%). Eight children had hemiplegia, 30 cases had diplegia, 21 cases had paraplegia, 33 cases had quadropelia, and 8 cases had ataxia. The samples were classified into GMFCS levels according to gross motor 


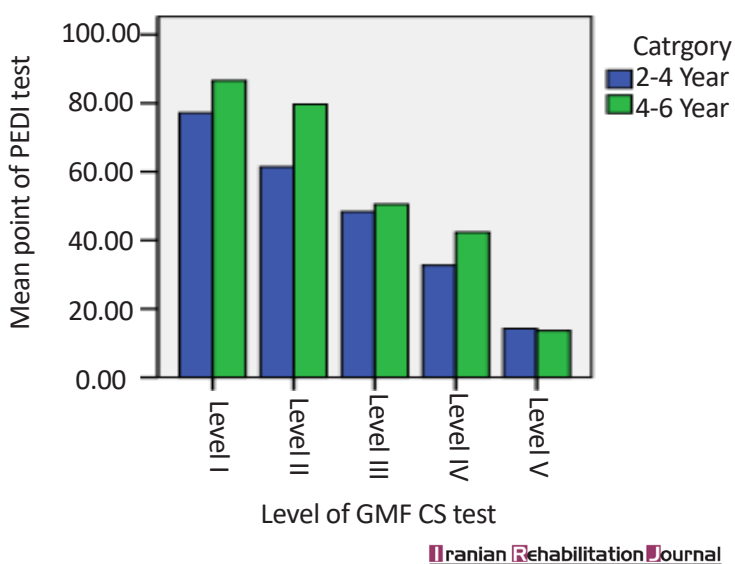

Figure 2. The mean social function score based on GMFCS levels in two age groups

function. The mean age of children was 49.08 years. The mean scores of children's social function in two groups according to the level of motor function are given in Table 1. According to the results of Kruskal-Wallis test, there was a significant difference between the mean score of social function in 5 levels of motor function in children with $\mathrm{CP}$ in both age groups $(\mathrm{P}<0.0001)$.

There was a weak and significant correlation between the mean score of social function and age of children using Spearman's correlation coefficient $(\mathrm{r}=0.265$ and $\mathrm{P}=0.008$ ) (Figure 1). Also, on comparing the social function score between the corresponding motor levels in GMFCS for the two age groups of 4-2 and 4-6 years, a significant difference was found between the two levels in level I ( $\mathrm{P}=0.002)$ and level II $(\mathrm{P}=0.002)$. However, in the other three levels, this difference was not significant $(0.53<\mathrm{P}<0.647)$ (Figure 2$)$. The comparison of the mean score of social function in males and females by MannWhitney test showed that there was no significant difference between the two groups $(\mathrm{P}=0.819)$ (Figure 3$)$.

\section{Discussion}

The results of this study indicate that there is a significant difference between the social function in the 5 levels of gross motor function of children with $\mathrm{CP}$, which means that the higher the level of motor function of these children, the lower are the social function scores allocated to them.

In previous studies, there was a significant relationship between the level of motor function and the daily capacity of the individual; one of those items is the capacity for social function [18]. Also, Ekstrom et al. (2005), after 5 months of functional training for children with $\mathrm{CP}$, observed significant changes in daily life activities, in-

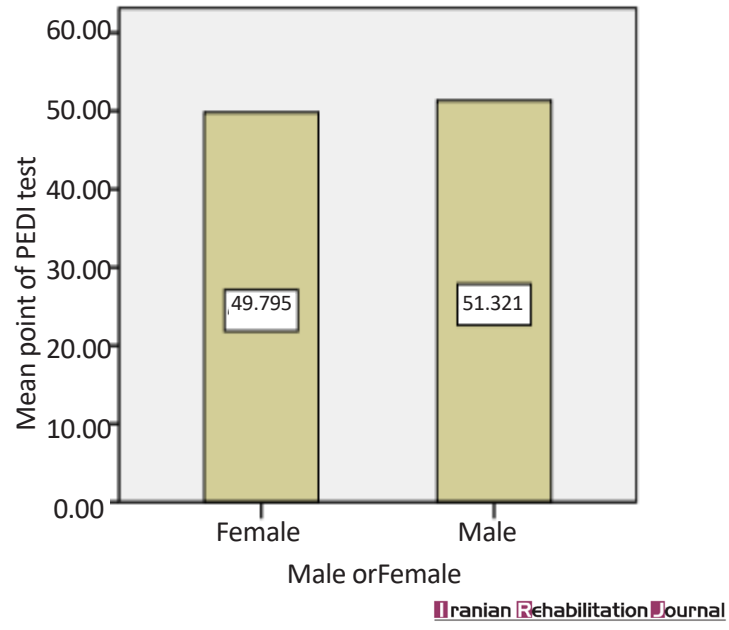

Figure 3. The mean social function score based on sex

cluding social function and levels of GMFCS of these children [19]. In addition, Diwan et al. (2014) conducted a study and found a negative correlation between GMFCS level and social function in PEDI. Therefore, children with a lower level of GMFCS had higher participation. As a result, the participation rate of these children depends on the degree of motor impairment [3]. These studies were performed using the instrument akin to those used in the present study whose results are consistent with the results of this study. However, the difference is that these studies did not examine the age of children and made no comparison with regard to the age group.

In the study of the relationship between age and social function, the findings showed that the increase in age may affect the growth of social function of children with $\mathrm{CP}$, but the correlation between these two is weak. In this regard, the social function score in the corresponding levels of GMFCS was compared in two age groups of 2-4 years and 4-6 years. The result of this comparison showed that only in two levels I and II, there was a significant difference between the social function score of two age groups, so it can be concluded from this report that if the motor problems of children with $\mathrm{CP}$ are high, the increase in age by itself cannot promote the social function of them. Also, no significant difference was found in social function scores between males and females. In 2009 , Robert Palisano et al. found that youth had more percentages of activities with friends and outdoors than children with CP. Similarly, children and youth in the first level of the GMFCS had more activity with friends than the other 4 levels. But in the section on out-of-home activities, persons at levels I, IV and V had a higher score than II and III levels. In this study, there was no difference between females and males [20]. As stated, the results of 
the studies by Palisano and his colleagues are in line with the present study, but in their research, the level of social activity in the corresponding levels of motor function were not compared in two separate age groups and the participants were assessed by the Children's Assessment of Participation and Enjoyment (CAPE). Whittingham and colleagues (2010) also found that in all three age groups $(18,24$, and 36 months), there was a significant correlation between the motor's level of children with $\mathrm{CP}$ and their social functioning score, and that the score was higher in the older age groups [2]. The results of this study are consistent with the present study, but in this study, the participants are all in the group of 2-4 years old GMFCS. Thus, the possibility of a more accurate comparison of variables in older and lower age groups with respect to the level of motion is absent. In 2013, Tan et al. in a longitudinal study, found that children at the 5th GMFCS level were significantly restricted in social development, and children who were at levels 1-4 had similar social growth status with better social growth than those at Level 5. In general, with increasing age, a certain increase was observed in their social growth [21]. In this study, the social development of children at levels 1 to 4 of GMFCS was roughly the same, while in the present study, there was a significant difference in the social function of children at different levels of GMFCS, which was not consistent with this study. This difference in the results of the two studies might pertain to differences in the instruments used to examine the social status of children with CP. In the study of Tan, social participation was assessed using the Vineland Adaptive Behavior Scales Survey.

\section{Conclusions}

A significant relationship was found between the level of gross motor function and social function of children with CP. Thus, it can be deduced that the greater the mobility problems of an individual, the more limited is the social function of the individual, and the less the mobility problems, the greater is the social function of these children. Also, in this study, the study of social function in two age groups and their comparison at the corresponding levels of GMFCS showed that with increasing motor constraints with age, no significant progress was made in the social function of children with CP. Therefore, in addition to physical interventions, social interventions should be considered for children with CP. Lack of cooperation of participants for completing the questionnaires, lack of responding to all items by participants were among the limitations of this study.

\section{Ethical Considerations}

\section{Compliance with ethical guidelines}

All participants were informed about study objectives and signed informed consents were obtained.

\section{Funding}

The present article was extracted from the Master thesis of Zohre Hasanvand in Department of Occupational Therapy, Shahid Beheshti University of Medical Sciences.

\section{Conflict of interest}

The authors declared no conflicts of interest.

\section{Acknowledgements}

Herby, we thank all professors who helped us in this research project. We also express our gratitude to authorities in Shahid Beheshti University of Medical Sciences.

\section{References}

[1] Khalaji M, Kalantari M, Shafiee Z, Hosseini MA. The effect of hydrotherapy on health of cerebral palsy patients: An integrative review. Iranian Rehabilitation Journal. 2017; 15(2):173-80. [DOI:10.18869/nrip.irj.15.2.173]

[2] Whittingham K, Fahey M, Rawicki B, Boyd R. The relationship between motor abilities and early social development in a preschool cohort of children with cerebral palsy. Research in Developmental Disabilities. 2010; 31(6):1346-51. [DOI:10.1016/j.ridd.2010.07.006] [PMID]

[3] Diwan S, Rathod N, Vyas N. Correlation between motor impairment and participation in children with cerebral palsy. International Journal of Contemporary Pediatrics. 2014; 1(2):7983. [DOI:10.5455/2349-3291.ijcp20140801]

[4] Bigham M. [Cerebral palsy theories, techniques \& treatment (Persian)]. Tehran: Danjeh Publication; 2006.

[5] Care A. Mosby's medical dictionary. St. Louis: Mosby; 2009.

[6] Kang LJ, Palisano RJ, Orlin MN, Chiarello LA, King GA, Polansky M. Determinants of social participation-with friends and others who are not family members - for youths with cerebral palsy. Physical Therapy. 2010; 90(12):1743-57. [DOI:10.2522/ptj.20100048] [PMID]

[7] Law M, Dunn W. Perspectives on understanding and changing the environments of children with disabilities. Physical \& Occupational Therapy in Pediatrics. 1994; 13(3):1-17. [DOI:10.1080/J006v13n03_01] 
[8] Russell DJ, Avery LM, Rosenbaum PL, Raina PS, Walter SD, Palisano RJ. Improved scaling of the gross motor function measure for children with cerebral palsy: Evidence of reliability and validity. Physical Therapy. 2000; 80(9):873-85. [DOI:10.1093/ptj/80.9.873] [PMID]

[9] Reddihough DS, Jiang B, Lanigan A, Reid SM, Walstab JE, Davis E. Social outcomes of young adults with cerebral palsy. Journal of Intellectual and Developmental Disability. 2013; 38(3):215-22. [DOI:10.3109/13668250.2013.788690] [PMID]

[10] Shevell MI, Dagenais L, Hall N. The relationship of cerebral palsy subtype and functional motor impairment: a population-based study. Developmental Medicine \& Child Neurology. 2009; 51(11):872-7. [DOI:10.1111/j.1469-8749.2009.03269.x] [PMID]

[11] van Schie PE, Siebes RC, Dallmeijer AJ, Schuengel C, Smits D-W, Gorter JW, et al. Development of social functioning and communication in school-aged (5-9years) children with cerebral palsy. Research in Developmental Disabilities. 2013 34(12):4485-94. [DOI:10.1016/j.ridd.2013.09.033] [PMID]

[12] Cadman D, Boyle M, Szatmari P, Offord DR. Chronic illness, disability, and mental and social well-being: Findings of the Ontario Child Health Study. Pediatrics. 1987; 79(5):805-13. [PMID]

[13] Beckung E, Hagberg G. Neuroimpairments, activity limitations, and participation restrictions in children with cerebral palsy. Developmental Medicine \& Child Neurology. 2002; 44(5):309-16. [DOI:10.1111/j.1469-8749.2002.tb00816.x]

[14] Dalvand H, Dehghan L, Feizy A, Hosseini SA. [Assessment of effect of Conductive Education (CE) on gross motor function in children with spastic Cerebral Palsy (3-6 year olds), in Vali-e-Asr Rehabilitation Foundation of Tehran (Persian)]. Archives of Rehabilitation. 2011; 11(5):26-30

[15] Dehghan L, Abdolvahab M, Bagheri H, Dalvand H, Faghih zade S. [Inter rater reliability of Persian version of Gross Motor Function Classification System Expanded and Revised in patients with cerebral palsy (Persian)]. Daneshvar Medicine. 2011; 18(91):37-44.

[16] Jalili N, Godarzi M, Rassafiani M, Haghgoo H, Dalvand H, Farzi M. The influenced factors on quality of life of mothers of children with severe cerebral palsy: A survey study. Journal of Modern Rehabilitation. 2013; 7(3):40-7.

[17] Moradi Abbasabadi M, Akbarfahimi N, Hosseini SA, Rezasoltani P. Reliability of the Persian Version of the pediatric evaluation of disability inventory in 3 to 9 -year old children with cerebral palsy. Journal of Mazandaran University of Medical Sciences. 2015; 25(130):129-37.

[18] Ostensjo S, Carlberg EB, Vollestad NK. Everyday functioning in young children with cerebral palsy: Functional skills, caregiver assistance, and modifications of the environment. Developmental Medicine \& Child Neurology. 2003; 45(09):603-12. [DOI:10.1111/j.1469-8749.2003.tb00964.x]

[19] Ahl LE, Johansson E, Granat T, Carlberg EB. Functional therapy for children with cerebral palsy: an ecological approach. Developmental Medicine \& Child Neurology. 2005; 47(9):613-9. [DOI:10.1111/j.1469-8749.2005.tb01213.x]

[20] Palisano RJ, Kang L-J, Chiarello LA, Orlin M, Oeffinger D, Maggs J. Social and community participation of children and youth with cerebral palsy is associated with age and gross motor function classification. Physical Therapy. 2009; 89(12):1304-14. [DOI:10.2522/ptj.20090162] [PMID]

[21] Tan SS, Wiegerink DJ, Vos RC, Smits DW, Voorman JM, Twisk JW, et al. Developmental trajectories of social participation in individuals with cerebral palsy: A multicentre longitudinal study. Developmental Medicine \& Child Neurology. 2014; 56(4):370-7. [DOI:10.1111/dmcn.12343] [PMID] 